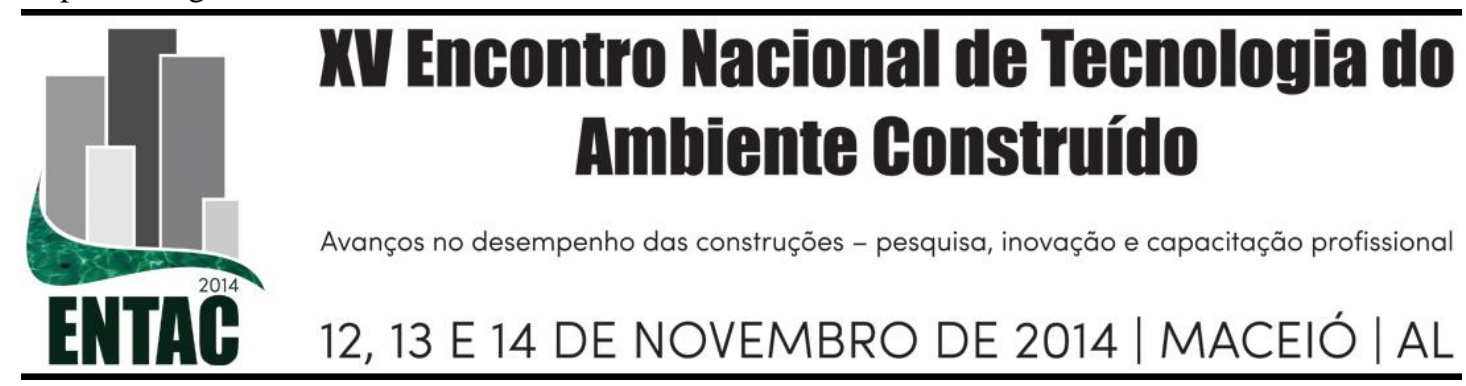

\title{
ESTUDO EXPERIMENTAL SOBRE A CAPACIDADE DE SOMBREAMENTO DE ESPÉCIES TREPADEIRAS PARA APLICAÇÃO EM CORTINAS VERDES
}

\author{
SCHERER, Minéia Johann (1); FEDRIZZI, Beatriz
}

(1) Universidade Federal do Rio Grande do Sul, mineiaarq@gmail.com (2) Universidade Federal do Rio Grande do Sul, beatrizfedrizzi@gmail.com

\begin{abstract}
RESUMO
As cortinas verdes caracterizam-se como dispositivos de controle solar, onde uma vegetação trepadeira desenvolve-se, auxiliada por suportes, em frente e afastada das superfícies verticais da edificação. A capacidade da vegetação de proporcionar sombra à fachada irá depender da densidade de sua folhagem, sendo que, quando adequadamente planejada, pode repercutir de forma positiva na eficiência energética da edificação. O objetivo deste artigo é verificar a capacidade de sombreamento de duas espécies trepadeiras, Wisteria floribunda e Campsis grandiflora, aptas para aplicação em sistemas de controle solar do tipo cortina verde para o clima subtropical brasileiro, observando o Percentual de Transmissão Solar (PTS) de sua folhagem, ao longo das diferentes estações do ano. Este estudo é parte integrante da tese de doutorado da autora, que está em andamento, sendo que os resultados aqui apresentados ainda são parciais. O método utilizado para esta pesquisa caracteriza-se como experimental e exploratório, uma vez que tem como base a construção de um protótipo de campo, onde as espécies de vegetação trepadeira foram plantadas e avaliadas através de fotografias. As imagens obtidas no local foram tratadas com o auxílio do software Adobe Photoshop@), com a separação entre as regiões cheias (folhagem) e vazadas, sendo por fim calculado o PTS em uma região delimitada de $1,0 \mathrm{~m}^{2}$ das plantas. Os resultados demonstraram uma significativa variação de densidade da folhagem das trepadeiras ao longo das estações, por serem espécies decíduas, com valores de PTS máximos no inverno e mínimos no verão. Este estudo, além de evidenciar os aspectos positivos do uso da vegetação no controle solar em arquitetura, também demonstra a viabilidade de aplicação da metodologia adotada, sendo que os dados obtidos representam valores médios e são plausíveis de utilização em simulações computacionais de desempenho energético de edificações.
\end{abstract}

Palavras-chave: Cortina verde; Vegetação; Desempenho energético; Controle solar.

\begin{abstract}
The green curtains are characterized as solar control devices, where climbing vegetation develops, aided by supporters in front and away from the vertical surfaces of the building. The capacity of the vegetation to provide shade to the facade will depend on the density of the foliage, when appropriately designed, can reflect positively on the energy efficiency of the building. The purpose of this article is to verify the two climbing plants species capacity of shading on the building: Wisteria floribunda and Campsis grandiflora, suitable for application in solar control systems like the green curtain to the Brazilian subtropical climate, noting the Percentage of Solar Transmission (PST) of these foliage throughout the different seasons. This study is part of this author doctoral thesis, which is ongoing, and the results presented in this article are still partial. The method used in this search is characterized as exploratory and experimental, as it is based on the construction of a prototype field where the climbing plants species were planted and evaluated by photographs. The images obtained were treated on site with support of Adobe Photoshop $\odot$ software, separating full areas (foliage) between empty areas, and finally calculated the PST in a $1.0 \mathrm{~m}^{2}$ area of plants. The results showed a significant variation in density of climbing plants foliage throughout the seasons, whereas deciduous species, with PST's values maximum in winter and
\end{abstract}


minimum in summer. This study show clearly the positive aspects of the use of vegetation architecture solar control and demonstrates the viability of applying the methodology, therefore the data represent mean values and plausible for use in computer simulations of energy performance of buildings.

Keywords: Green curtain; vegetation; Energy performance; Solar control.

\section{INTRODUÇÃO}

As cortinas verdes caracterizam-se como dispositivos de controle solar, onde uma vegetação trepadeira desenvolve-se, auxiliada por suportes, em frente e afastada das superfícies verticais da edificação. A capacidade da vegetação de proporcionar sombra à fachada irá depender da densidade de sua folhagem, sendo que, quando adequadamente planejada, pode repercutir de forma positiva na eficiência energética da edificação. Diferente dos sistemas convencionais, o uso da vegetação como proteção solar em fachadas, ainda pode apresentar outros benefícios, na medida em que responde de forma dinâmica às variações do clima e das estações, é um elemento natural e de baixo impacto ambiental, além de representar uma nova possibilidade de revegetação para as cidades.

A maior parte do território brasileiro possui grande incidência de radiação solar e altas temperaturas o ano todo. Mesmo na região sul, onde a latitude é maior, o verão registra temperaturas elevadas. Sendo assim, deve-se evitar o excesso de insolação nos ambientes internos, o que provoca indesejável carga energética. A solução, na maioria das vezes, pode ser obtida com a adoção de dispositivos de proteção solar, sobretudo para as áreas transparentes de fachada, de forma a bloquear ou redirecionar a incidência dos raios solares. Dentro deste contexto, a vegetação, mesmo sendo um elemento natural, possui uma estrutura de galhos e folhas capazes de minimizar a passagem da radiação.

Atualmente, com o aumento gradativo de conhecimento e disponibilidade técnica, as cortinas verdes estão assumindo seu papel na arquitetura, sistematizando o uso da vegetação trepadeira no controle solar e também como elemento de composição arquitetônica, cumprindo uma importante função e proporcionando marcante efeito visual. Alguns exemplares significativos de edificações construídas com esta técnica já podem ser encontrados em todas as partes do mundo, como se observa nas imagens da Figura 1, de edificações no Chile, Europa e países asiáticos.

\section{Figura 1 - Edificações construídas com cortinas verdes}
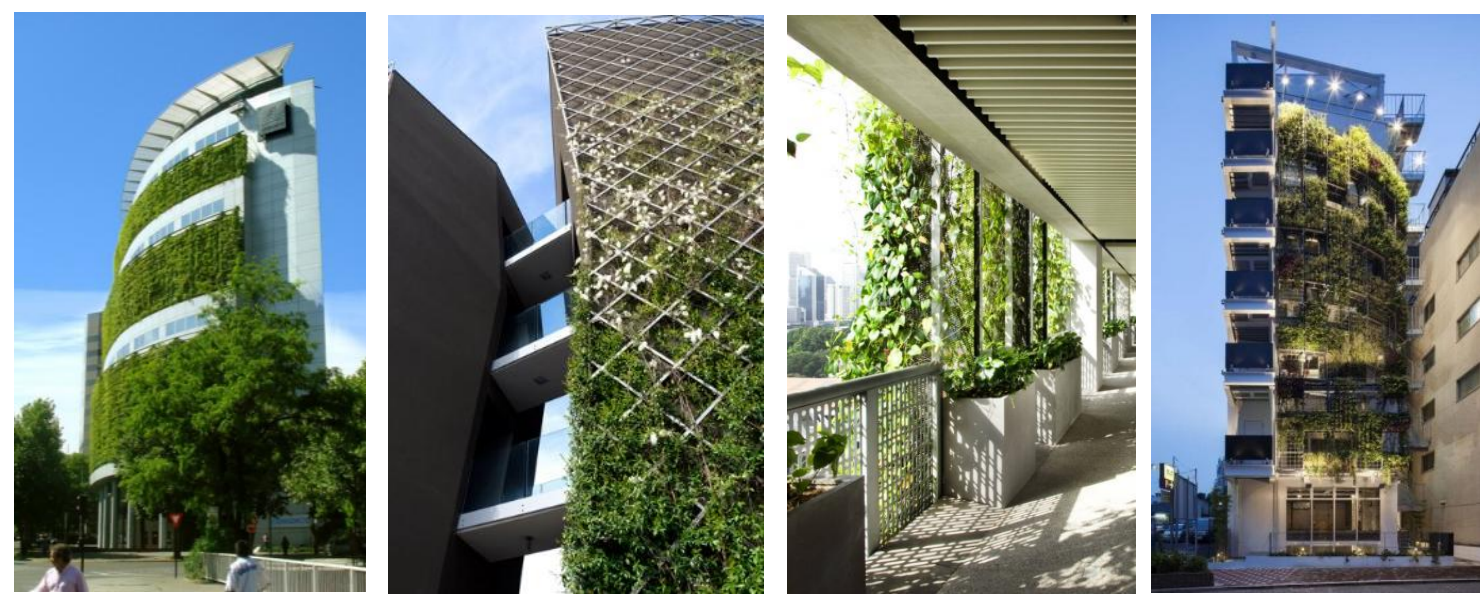

Fonte: Enrique Browne y Asociados (2013); Mario Cucinella Architects (2013); Archdaily (2013); Contemporist (2013) 
Uma das principais limitações no estudo das cortinas verdes, enquanto elemento de controle solar, é o seu dinamismo. Um dispositivo de proteção solar convencional será dimensionado com unidades de tamanho fixo, que não se alteram com o tempo, sendo que a maior possibilidade de variação estará relacionada ao movimento de abrir ou fechar suas aletas ou orifícios. A vegetação, no entanto, é um elemento vivo e que sofre alterações ao longo do seu crescimento, das variações sazonais e por causas adversas, seja interferência humana, variações climáticas ou problemas de adaptabilidade. Além disso, cada espécie de vegetal possui características diferenciadas que irão influenciar na sua capacidade de sombreamento, como por exemplo, o maior ou menor grau de fechamento da folhagem, sua velocidade de crescimento, seu porte, folhas perenes ou caducifólias. Estes aspectos também sofrem variações dependendo das condições de plantio, adubação e irrigação, podendo ser intensificados ou apassivados.

Este dinamismo gera dificuldade de previsão da condição da vegetação ao longo do tempo e, por conseguinte, de quantificação de sua capacidade de sombreamento, de forma a ser possível avaliar sua influência no desempenho energético das edificações, em procedimentos de cálculo ou simulação computacional. Mesmo com esta dificuldade evidente, considera-se, pela contemporaneidade do tema e pelo interesse cada dia mais evidente no uso das cortinas verdes em projetos de arquitetura, que pesquisas científicas, alicerçadas em bases metodológicas consistentes, são de grande valia e necessárias para o aprimoramento e difusão desta técnica.

Desta forma, o objetivo deste artigo é verificar a capacidade de sombreamento de duas espécies trepadeiras, Wisteria floribunda e Campsis grandiflora, aptas para aplicação em sistemas de controle solar do tipo cortina verde para o clima subtropical do País, observando o Percentual de Transmissão Solar (PTS) de sua folhagem, ao longo das diferentes estações do ano. Este trabalho é parte integrante de uma pesquisa mais ampla que está em andamento, que irá contemplar a avaliação completa destas e de outras espécies trepadeiras.

\section{REVISÃO BIBLIOGRÁFICA}

Um dos primeiros estudos relevantes realizados em laboratório e focados no uso da vegetação como elemento de controle solar foi desenvolvido por Stec, Passen e Maziarz (2005), com o objetivo de avaliar o rendimento térmico e as habilidades de um sistema com vegetação trepadeira localizado na cavidade de fachadas duplas envidraçadas, comparando seu desempenho com um sistema de veneziana tradicional. Os resultados demonstraram que o sombreamento com plantas se mostra mais eficaz do que com venezianas, com redução da temperatura superficial e na camada interna.

Outro estudo importante, este realizado in loco, foi a avaliação do comportamento energético do edifício Consorcio Santiago, no Chile, apresentado na Figura 1. O edifício foi analisado por Reyes (2002 apud BROWNE, 2007), comparando dois pavimentos do prédio: um sem a vegetação como elemento de sombreamento e outro com a cortina verde. $\mathrm{O}$ resultado apontou que o pavimento protegido consome $35 \%$ menos de energia, como uma redução de $25 \%$ nos custos. Isto demonstra, mesmo que ainda empiricamente, os benefícios térmicos e energéticos da adoção desta solução.

Por sua vez, Pérez (2010) realizou uma investigação sobre o comportamento de cortinas verdes no clima mediterrâneo continental seco da Espanha. O experimento foi elaborado com o objetivo de comparar o crescimento de quatro diferentes espécies de vegetação trepadeira e sua capacidade de fornecer sombra. Os resultados demonstraram que a desempenho de bloqueio da radiação solar das plantas pode ser comparado aos melhores índices alcançados por barreiras artificais, o que favorece a sua aplicação como elemento de proteção solar em fachadas. A capacidade de sombreamento mais favorável 
foi o da Parthenocissus quinquefolia, que atingiu uma média de transmissão de luz de 0,15 .

Outro experimento, realizado na Universidade de Brighton (Reino Unido) por Ip, Lam e Miller (2010), teve como objetivo principal a elaboração de uma metodologia para a determinação de um coeficiente de sombreamento dinâmico, chamado "Bioshading", que refletisse um ciclo anual de crescimento da planta. Para tanto, foram instaladas duas cortinas verdes em salas de escritório, com a espécie Parthenocissus quinquefolia, sendo os dados de radiação solar coletados regularmente, em frente e atrás da vegetação. A transmitância solar chegou a 0,47 no verão, reduzindo gradativamente até 0,95 no período sem folhas.

Mais recentemente, na Tailândia, país que vem adotando políticas de incentivo ao uso da vegetação em jardins verticais e, especialmente, na forma das cortinas verdes para sombreamento, os pesquisadores Sunakorn e Yimprayoon (2011) estudaram o uso de plantas trepadeiras como dispositivos de sombra verticais, aplicando a espécie Thunbergia grandiflora na fachada oeste de uma sala de aula ventilada naturalmente. $\mathrm{O}$ objetivo principal do experimento era comparar a temperatura interna desta sala com outra de mesmas condições, localizada ao lado, porém sem a cortina verde. Os resultados demonstraram que a temperatura interna ficou menor no ambiente com a vegetação, sobretudo durante o dia, devido ao sombreamento causado pela planta e também pelo processo de evapotranspiração do vegetal.

No Brasil, as pesquisas sobre sistemas verdes em fachadas são ainda mais recentes e escassas. Um dos poucos estudos foi desenvolvido por Morelli (2009), com o objetivo de avaliar, através de um experimento em células-teste, o desempenho térmico da espécie Parthenocissus Tricuspidata. Comprovou uma diminuição da temperatura interna de, em média, $0,9^{\circ} \mathrm{C}$ na célula-teste com trepadeira aderente e de até $2,6^{\circ} \mathrm{C}$ na célula-teste com trepadeira sobre treliça afastada da parede.

Todos estes estudos evidenciam que os aspectos positivos, os benefícios do uso da vegetação superam os possíveis pontos negativos, embora estes possam ser decisivos no momento do planejamento da edificação. Certamente ainda existe uma grande hesitação na área da arquitetura e construção civil em implementar sistemas verticais com vegetação. Isto se deve, entre outros aspectos, aos custos inicias envolvidos, necessidade de conhecimento técnico adequado, de manutenção extra, possibilidade de gerar patologias ou atrair fauna indesejada.

Em uma análise financeira, desta forma, deve-se considerar no cálculo do custo/benefício outros aspectos que direta ou indiretamente afetam o ciclo de vida em longo prazo da edificação: menores custos de energia para climatização, aumento do valor estético e ecológico, possibilidade de valorização do imóvel ou de melhor condição de vida para os ocupantes.

\section{MATERIAIS E MÉTODO}

O método utilizado para esta pesquisa caracteriza-se como experimental e exploratório, uma vez que tem como base a construção de um protótipo de campo, onde diferentes espécies de vegetação trepadeira foram plantadas e avaliadas através de fotografias, a fim de se obter o Percentual de Transmissão Solar (PTS) em cada estação do ano. As etapas de execução do protótipo experimental e de coleta e tratamento dos dados serão detalhadas a seguir. 


\subsection{Execução do protótipo experimental}

O experimento consiste na construção de um protótipo simplificado, que simula a situação de aplicação das cortinas verdes, em pequena escala. O modelo está sendo considerado simplificado por não agregar o elemento edificação ao arranjo, ou seja, considerar somente a cortina verde, de forma isolada, sem vínculo com uma área construída específica. O protótipo foi executado na cidade de Formigueiro, na região central do Estado do Rio Grande do Sul, que possui clima subtropical, com as estações do ano bem definidas.

Foi construída uma estrutura com tela metálica, com 6,0 metros de comprimento por 1,5 metros de altura, posicionada com as faces da tela voltadas para a orientação Leste e Oeste. O espaço total foi subdividido em regiões, destinadas ao desenvolvimento de cinco diferentes espécies de trepadeiras. Desde a época do plantio das primeiras mudas, em setembro de 2011, as espécies foram monitoradas em seu crescimento e adaptação, sendo que em dados momentos, algumas escolhidas inicialmente, foram substituídas por outras que apresentaram melhor resposta às condições climáticas e necessidades do experimento. $\mathrm{O}$ acompanhamento deste período de consolidação incluiu visitas regulares para irrigação, adubação, fixação dos novos galhos e registro fotográfico.

As avaliações definitivas, com registro fotográfico e tratamento das imagens, foram programadas para acontecer no período de um ano, desde junho de 2013 até maio de 2014, entre os dias 15 e 20 de cada mês. Para o presente artigo são apresentados os resultados de somente duas espécies: Wisteria floribunda (Glicínia) e Campsis grandiflora (Trombeta-chinesa), considerando-se os meses de início de cada estação: junho (inverno), setembro (primavera), dezembro (verão) e março (outono).

\subsection{Procedimento de coleta e tratamento dos dados}

A seguir será descrito o procedimento de coleta e tratamento dos dados para determinação do PTS das espécies que constituem o protótipo experimental e foram consideradas neste artigo. A mesma metodologia será aplicada em todas as vegetações, na avaliação definitiva da pesquisa completa, acontecendo no período de doze meses, uma vez por mês em cada espécie, a fim de mapear a variação completa de sua condição nas diferentes estações do ano.

O Percentual de Transmissão Solar (PTS) de cada vegetação foi calculado através do tratamento de imagens obtidas no local, delimitando-se $1,0 \mathrm{~m}^{2}$ de área da planta. As imagens fotográficas foram tomadas na frontal e ortogonalmente ao protótipo experimental, pelo lado de incidência do sol do período da tarde (Oeste), com câmera digital, modelo DSC-WX7, do fabricante Sony. Para facilitar o tratamento das imagens, com melhor identificação dos cheios e vazios por contraste, foi posicionado atrás da vegetação um painel de madeira pintado na cor branca (Figura 2-a). A localização do painel foi definida como o mais próximo possível da vegetação, sem, no entanto, interferir na disposição dos galhos ou "amassar" suas folhas.

A partir das imagens fotográficas originais do local, foi utilizado o software Adobe Photoshop $($ para tratamento e compilação dos dados. Conforme o exemplo, inicialmente a imagem é recortada nas dimensões do painel (Figura 2-b) e após é delimitada a região de 1,0 $\mathrm{m}^{2}$ que será analisada em cada espécie (Figura 2-c). 


\section{Figura 2 - Exemplo da sequência de obtenção e tratamento das imagens}

(a)

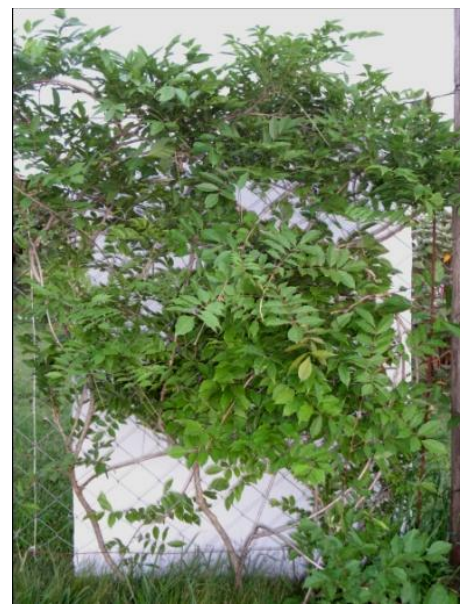

(b)

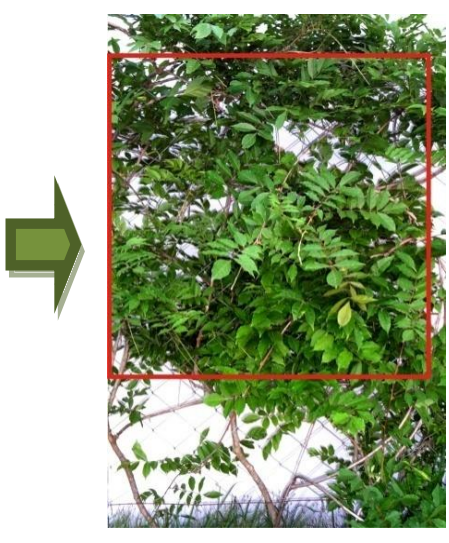

(c)

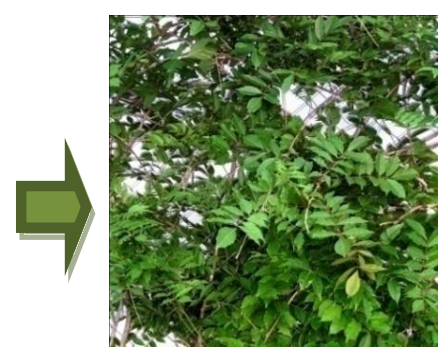

Fonte: Acervo do autor (2013)

A partir de então, inicia-se o processo de separação entre o que efetivamente é componente da vegetação e o que está vazado ou faz parte da estrutura metálica entre as folhas. Foi desta forma, subtraído da imagem qualquer elemento ou região visível que não fazia parte da planta, com auxílio das ferramentas do software Adobe Photoshop ( "varinha mágica" e "borracha", como pode ser observado a seguir, na Figura 3. O fundo de cor vermelho foi adotado para facilitar a visualização das regiões vazadas.

De posse das imagens tratadas, com a separação das regiões que compunham o objeto e o fundo, foi utilizada a ferramenta de contagem de pixels, de forma a calcular a área preenchida pela vegetação e a área vazada. Para a contagem dos pixels, inicialmente é necessário dimensionar a imagem, sendo que foi definida a ocorrência de 20 px/cm, ou seja, para a área delimitada de $1,0 \mathrm{~m}^{2}, 2000$ pixels na horizontal e 2000 pixels na vertical, totalizando $4,0 \times 10^{6}$ pixels. Após, eram selecionados todos os objetos existentes na imagem, no caso as regiões de folhagem, e realizada a contagem dos pixels, sendo que o resultado já é expresso em fração da área total. Por fím, realizava-se a seleção "inversa", ou seja, dos vazios entre as folhas e calculava-se novamente a fração da área total, sendo esta, portanto, o Percentual de Transmissão Solar (PTS) obtido na imagem.

Este valor de PTS pode ser considerado, então, como correspondente à média de transmissão solar direta para cada metro quadrado da cortina verde que compõem uma fachada, considerando uma situação aproximadamente homogênea de distribuição desta mesma espécie, nesta condição de crescimento e época do ano.

\section{Figura 3 - Exemplo da subtração do fundo, na espécie Wisteria floribunda}
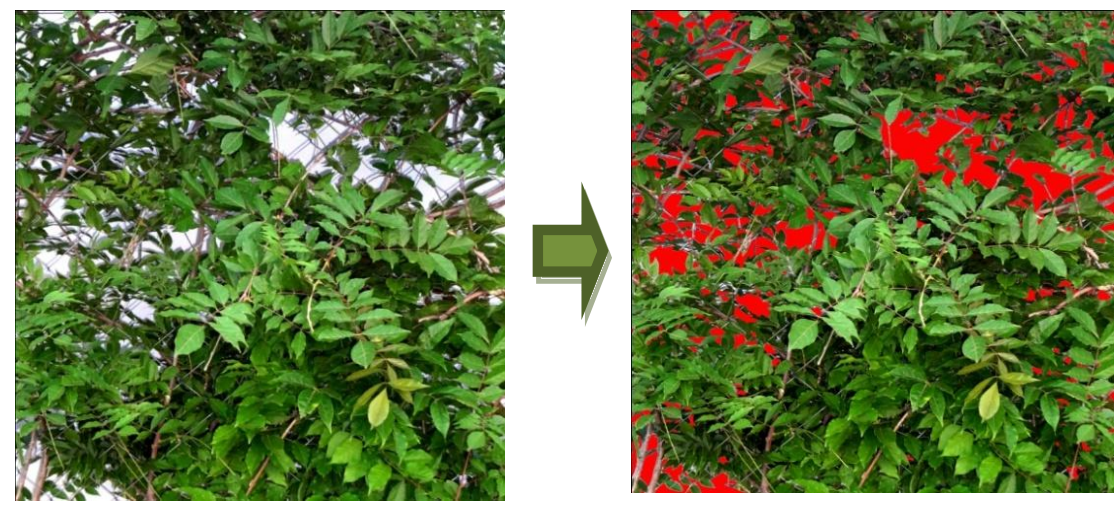

Fonte: Acervo do autor (2013) 


\section{RESULTADOS E DISCUSSÕES}

Os resultados são apresentados, inicialmente, através do tratamento das imagens, realizando a análise e discussão sobre o Percentual de Transmissão Solar (PTS) obtido em cada espécie, bem sua variação ao longo das estações do ano.

A primeira espécie a ser analisada é Wisteria floribunda (Glicínia), sendo que o resultado das imagens tratadas e do cálculo do Percentual de Transmissão Solar (PTS), nos meses correspondentes ao início de cada estação do ano, encontram-se a seguir, ilustrados pelas Figuras 4 e 5.

Já para a segunda espécie avaliada, Campsis grandiflora (Trombeta-chinesa), os resultados das imagens tratadas e do cálculo do Percentual de Transmissão Solar (PTS), nos mesmos meses, encontram-se ilustrados pelas Figuras 6 e 7.

\section{Figura 4 - Resultado das imagens tratadas e cálculo do PTS na espécie Wisteria} floribunda

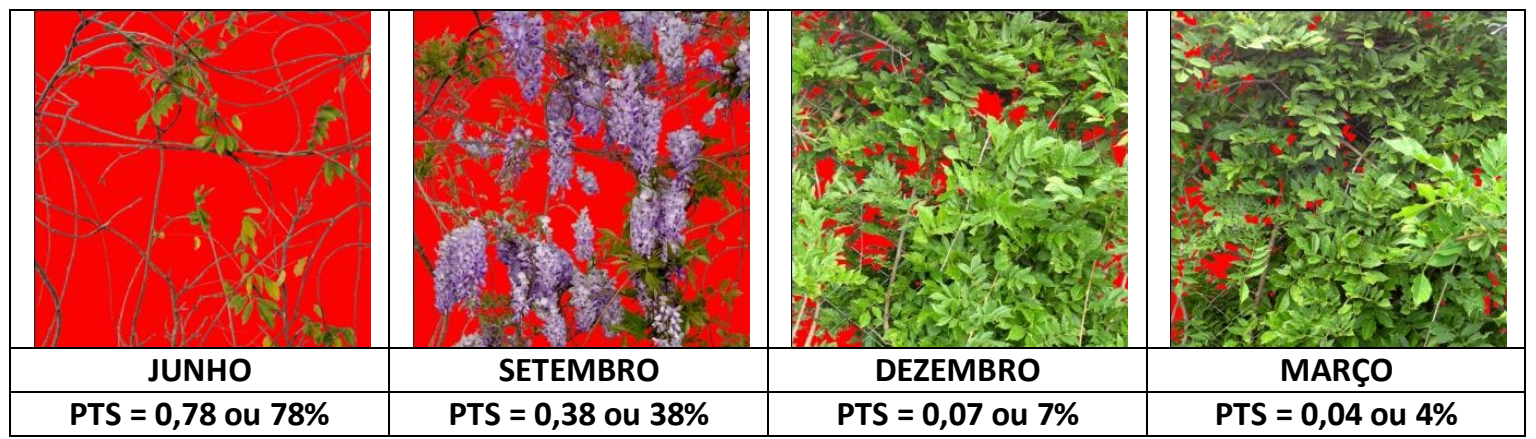

Fonte: Acervo do autor (2013)

Figura 5 - Gráfico da variação do PTS, na espécie Wisteria floribunda

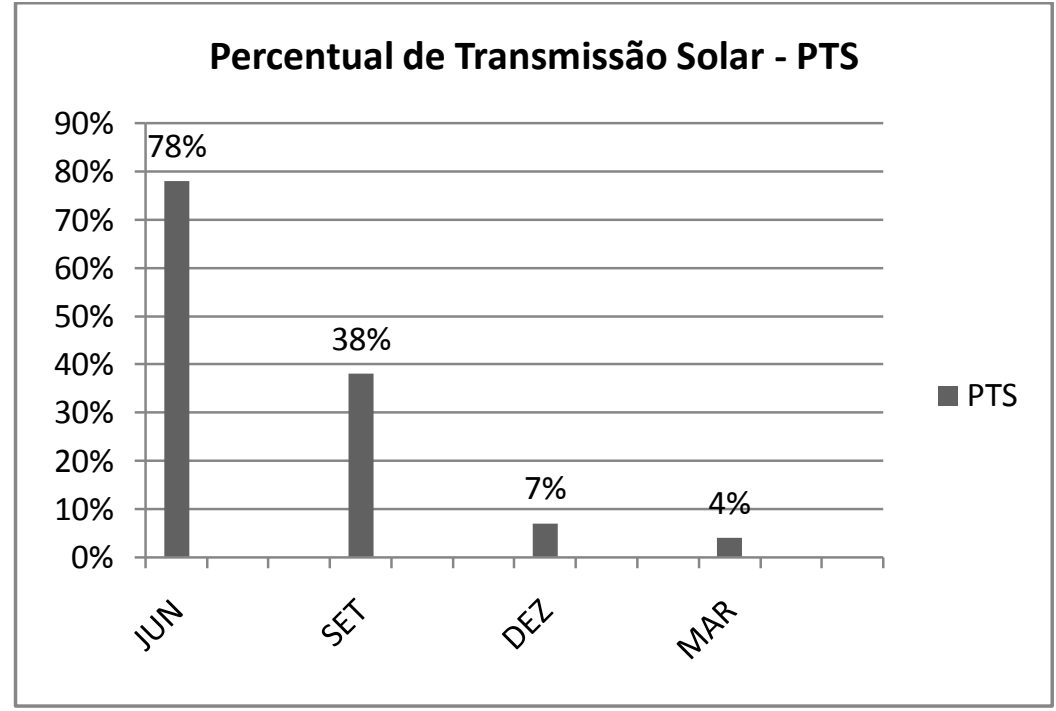

Fonte: Acervo do autor (2013) 


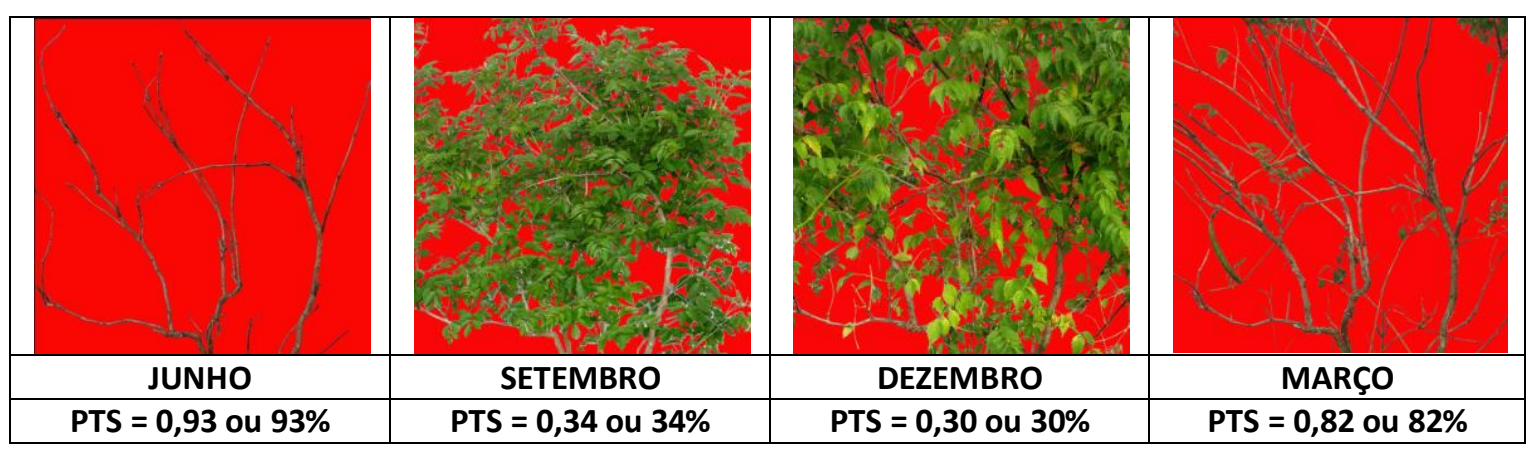

Fonte: Acervo do autor (2013)

\section{Figura 7 - Gráfico da variação do PTS, na espécie Campsis grandiflora}

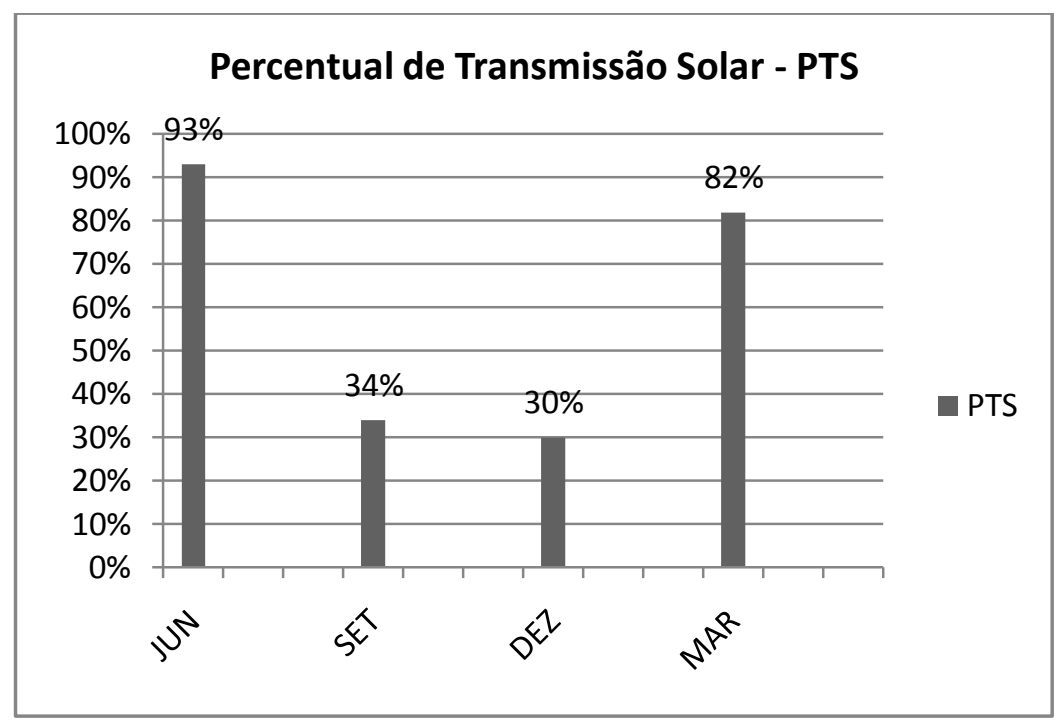

Fonte: Acervo do autor (2013)

Os resultados demonstraram uma significativa variação de densidade da folhagem das duas espécies trepadeiras ao longo do ano, e, por conseguinte, de sua transmissão solar (PTS). Isto se deve ao fato das espécies serem caducifólias, perdendo parcial ou totalmente suas folhas no período mais frio do ano. A Trombeta-chinesa possui um ciclo de brotação e decaimento das folhas bem definido, estando praticamente seis meses com folhagem (primavera e verão) e seis meses somente com a presença da galharia (outono e inverno). Por este motivo, o PTS variou de 82 a $93 \%$ no período sem folhas, até valores entre 30 e $34 \%$ no verão e primavera, com a presença expressiva da folhagem e também da floração.

Já a Glicínia também perde suas folhas no inverno, porém apresenta uma floração muito expressiva no final desta estação e início da primavera. Deste modo, a variação do PTS é mais gradativa, com valores mínimos de transmissão solar no verão (7\%) e outono (4\%) e máximos no inverno $(78 \%)$. Na primavera, justamente em função do aparecimento da floração, o PTS é intermediário, chegando a uma média de $38 \%$.

Considerando a aplicação destas espécies em cortinas verdes de edificações do sul do País, onde o clima predominante é subtropical, esta variação de densidade da folhagem pode representar condição favorável para o desempenho energético tanto no verão como 
no inverno. Na situação de verão, um maior sombreamento da fachada, principalmente das regiões envidraçadas, será desejável como forma de reduzir a insolação direta e, por conseguinte, a carga térmica que chega ao edifício. Já no período de inverno, um certo grau de acesso do calor pode ser útil ao aquecimento do prédio, sobretudo em edificações de uso residencial. Nestas duas condições extremas, assim como nas situações intermediárias da primavera e do outono, o uso da vegetação caducifólia na cortina verde pode auxiliar na redução do consumo de energia para resfriamento ou aquecimento da edificação.

Cabe ressaltar que, para outra condição climática, onde há predominância do calor, possivelmente as espécies mais adequadas sejam as perenes ou semi-caducifólias, que mantém uma condição de sombreamento maior durante todo o ano. Outra consideração relevante diz respeito ao uso da edificação, onde uma residência provavelmente vai necessitar de maior carga de aquecimento no inverno do que um prédio comercial ou institucional, tendo em vista que estes já geram elevada carga térmica interna pelo uso de equipamentos e sistemas de iluminação.

Estas observações comprovam a necessidade de estudos e conhecimentos avançados para a execução das cortinas verdes, com a correta escolha das espécies para cada situação, do seu sistema de fixação e de sua distribuição na fachada, de forma a se obter maior ou menor grau de fechamento ou permeabilidade. $\mathrm{O}$ estudo experimental aqui apresentado, portanto, apresenta dados de sombreamento que podem auxiliar os projetistas na avaliação do desempenho deste sistema de controle solar, com aplicação dos valores de PTS em simulações computacionais de eficiência energética. A intenção do estudo completo é fornecer dados mensais e de um maior número de espécies trepadeiras, realizando simulações em diferentes condições climáticas e orientação solar das fachadas. Após, os valores podem ser generalizados para outras espécies com características morfológicas semelhantes.

\section{CONSIDERAÇÕES FINAIS}

O objetivo deste artigo foi apresentar e discutir um sistema de controle solar diferenciado para aplicação em projetos arquitetônicos: as cortinas verdes, com uso de vegetação trepadeira nas fachadas. O enfoque principal foi dado à quantificação da capacidade de sombreamento de algumas espécies e como isto pode repercutir na eficiência energética da edificação.

As principais conclusões referem-se ao evidente grau de variação do Percentual de Transmissão Solar (PTS), nas diferentes espécies e também ao longo do ano, com a modificação das condições climáticas. No caso das duas espécies avaliadas, por serem decíduas, os valores de PTS foram máximos no inverno e mínimos no verão, ou seja, há predominância de vazados no inverno, por onde a radiação solar encontra caminho direto para atravessar a planta e atingir a edificação. Por outro lado, no verão, a presença da folhagem com maior densidade evita a passagem de grande parte dos raios solares, causando sombreamento e diminuindo a carga térmica no interior do prédio.

Outra consideração importante refere-se ao dinamismo da vegetação, como foi dito, o que gera dificuldade de previsão de sua condição ao longo do tempo, que pode ser diferenciada de um ano para outro. Neste caso os dados coletados, embora já médios, podem sofrer alterações significativas.

Desta forma, este estudo, além de evidenciar os aspectos positivos do uso da vegetação no controle solar em arquitetura, também demonstra a viabilidade de aplicação da metodologia adotada, considerando suas simplificações e tendo em vista que os dados 
obtidos representam valores médios e são plausíveis de utilização em simulações computacionais de desempenho energético de edificações.

A pesquisa completa que está sendo desenvolvida na tese de doutorado da autora também contará com a elaboração de uma série de diretrizes básicas que possam orientar projetistas para a aplicação das cortinas verdes em arquitetura, promovendo seu uso e favorecendo o sucesso de seu desempenho.

\section{REFERÊNCIAS}

ARCHDAILY. Disponível em <http://www.archdaily.com/217481/school-of-the-artswoha/sota-3-2011-pbh-020/>, acesso em 20 fev. 2013.

BROWNE, E. El Edificio “Consorcio-Santiago" 14 Años Después. Santiago, 2007. Disponível em: <http://www.ebrowne.cl>, acesso em: 10 mar. 2011.

CONTEMPORIST. Disponível em <http://www.contemporist.com/2013/03/29/vent-vert-byedward-suzuki-associates/>, acesso em 12 abr. 2013.

ENRIQUE BROWNE Y ASOCIADOS. Disponível em <http://www.ebrowne.cl>, acesso em 20 fev. 2013.

IP, K., LAM, M., MILLER, A. Shading performance of a vertical deciduous climbing plant canopy. Building and Environment, n. 45, p. 81-88, 2010.

MARIO CUCINELLA ARCHITECTS. Disponível em <http://www.mcarchitects.it/project/centro-direzionale-forum>, acesso em 20 fev. 2013.

MORELLI, D. D. O. Paredes verdes: vegetação como qualidade ambiental no espaço construído. 2009. Dissertação (mestrado). Curso de Pós-Graduação em Engenharia Civil, Universidade Estadual de Campinas, Campinas, 2009.

PÉREZ, G. Façanes vegetades: estudi del seu potencial com a sistema passiu d'estalvi d'energia, en clima mediterrani continental. Tese (doutorado). Programa de Doctorado Ámbits de Recerca de la Construcció i l'Energía a l'Arquitectura. Universitat Politècnica de Catalunya, Barcelona, 2010.

STEC, W. J., PASSEN, A. H. C., MAZIARZ, A. Modelling the Double skin façade with plants. Energy and Buildings, n. 37, p. 419-427, 2005.

SUNAKORN, Pasinee; YIMPRAYOON, Chanikarn. Thermal performance of biofacade with natural ventilation in the tropical climate. Procedia Engineering, n. 21, p. 34-41, 2011. 